\title{
Pengaruh Lokasi dan Kualitas Pelayanan Terhadap Kepuasan Pelanggan Pada Jasa Pengiriman J \& T di Muara Bulian
}

\author{
M. Aziz Mukhlis \\ Sekolah Tinggi Ilmu Ekonomi Graha Karya Muara Bulian \\ Email : azizmukhlis29@gmail.com
}

\begin{abstract}
Bussiness world competition currently is more progressively tight. It is also perceived by services $J \& T$ In muara bulian. $J \& T$ is demanded to understand about the factors that can influence their customer's satisfaction. $J \& T$ have to make some improvement and innovation that can increasing their customer's satisfaction. The research aims to analyze how the influence of service quality, and location toward customer satisfaction. Sample of the research is 81 customer and then an analysis is performed toward the obtained data by using data analysis quantitatively and qualitatively. Quantitatively analysis includes: validity and realibility test, classical assumption test, multiple regression analysis and hypothesis test through $t$ and $F$ test, and determination coefficient analysis $\left(R^{2}\right)$. Qualitative analysis is an interpretation of the obtained data within research and the result of data processing has been implemented by providing information and explanation. Data has complied validity, realibility and classical test is processed, so that those are resulting regression equation as follows: Where, $Y=a+b 1 X 1+b 2 X 2$ Customer Satisfaction (Y), Service Quality variable (X1), service qualitu variable (X2), and Location variable (X3). Hyphothesis test uses test demonstrates that the three of examined independent variables is proved significantly have a partially effect on dependent variable of Customer Satisfaction. Then, follow the F test can be recognized that the three of examined independent variables has a simultaneously effect on dependent variable of Customer Satisfaction
\end{abstract}

Keyword: the influence of the location; quality of service; Customer Satisfaction

DOI: 10.33087 /ekonomis.v3i1.50

\section{PENDAHULUAN}

Semakin banyaknya masyarakat yang menggunakan jasa pengiriman, maka kualitas pelayanan menjadi sangat penting untuk memenangkan persaingan, apa yang diinginkan dan diharapkan oleh konsumen dari kualitas pelayanan yang diberikan, maka akan didapat suatu nilai tambah tersendiri bagi perusahaan tersebut. Kualitas pelayanan perlu mendapat perhatian besar dari perusahaan, karena kualitas pelayanan mempunyai hubungan langsung dengan kemampuan bersaing dan tingkat keuntungan perusahaan.

Salah satu kunci sukses nya suatu usaha adalah penentuan lokasi, lokasi dimulai dengan memilih komunitas. Adisetiawan (2016) menyatakan bahwa memilih tempat atau lokasi yang baik merupakan keputusan yang penting karena tempat merupakan komitmen sumber daya jangka panjang yang dapat fleksibilitas masa depan usaha. Lokasi akan mempengaruhi pertumbuhan di masa depan. Area yang dipilih haruslah mampu tumbuh dari segi ekonomi sehingga dapat mempertahankan kelangsungan usahanya. Adisetiawan (2017) mengungkapkan bahwa kualitas pelayanan adalah suatu cara kerja perusahaan yang berusaha mengadakan perbaikan mutu secara terus-menerus terhadap proses, produk dan service yang dihasilkan perusahaan. Sedangkan menurut Tjiptono dan Chandra (2011), kualitas pelayanan merupakan upaya pemenuhan kebutuhan dan keinginan konsumen serta ketepatan penyampaiannya dalam mengimbangi harapan konsumen. Kualitas pelayanan dapat diukur dengan lima dimensi sesuai dengan urutan derajat kepentingan relatifnya (Tjiptono dan Chandra, 2011), yaitu keandalan, jaminan, bukti fisik, empati dan daya tanggap.

Pelayanan yang berkualitas berperan penting dalam membentuk kepuasan konsumen, selain itu juga erat kaitannya dalam menciptakan keuntungan bagi perusahaan. Semakin berkualitas pelayanan yang diberikan oleh perusahaan maka kepuasan yang dirasakan oleh pelanggan akan semakin tinggi. Menurut Kotler dan Keller (2009) kepuasan adalah perasaan senang atau kecewa seseorang yang berasal dari perbandingan antara kesannya terhadap kinerja (atau hasil) suatu produk dan harapan-harapannya. Perusahaan akan berhasil memperoleh pelanggan dalam jumlah yang banyak apabila dinilai dapat memberikan kepuasan bagi pelanggan. Ketika pelanggan telah merasa puas maka akan terjalin hubungan harmonis antara produsen dan konsumen, menciptakan dasar yang baik bagi pembelian ulang dan membentuk rekomendasi dari mulut ke mulut yang dapat menguntungkan sebuah perusahaan. Kepuasan konsumen terhadap perusahaan jasa diartikan sebagai suatu keadaan dimana harapan konsumen terhadap suatu pelayanan sesuai dengan kenyataan yang diterima tentang pelayanan yang diberikan kepada konsumen. Jika pelayanan suatu perusahaan jasa tersebut jauh dibawah harapan konsumen maka konsumen akan kecewa. Sebaliknya, jika layanan yang 
Pengaruh Lokasi dan Kualitas Pelayanan Terhadap Kepuasan Pelanggan Pada Jasa Pengiriman J \& T di Muara Bulian

diberikan memenuhi harapan konsumen, maka konsumen akan senang. Harapan konsumen dapat diketahui dari pengalaman mereka sendiri saat menggunakan pelayanan suatu perusahaan jasa, omongan orang lain dan informasi iklan. JNE sebagai perusahaan yang bergerak dalam bidang jasa dituntut untuk memberikan pelayanan yang berkualitas kepada pelanggannya.

\section{Bauran Pemasaran}

Bauran pemasaran adalah seperangkat alat pemasaran yang digunakan perusahaan untuk mencapai tujuan pemasaraan di dalam pasar sasaran. Bauran pemasaran merupakan variabel-variabel terkendali yang dapat digunakan perusahaan untuk mempengaruhi konsumen dari segmen pasar tertentu yang dituju perusahaan (Kotler 2009). Kotler (2009) mempopulerkan sebuah kelasifikasi 4 (empat) unsur dari bauran pemasaraan yang dikenal dengan 4P yaitu produk (product), harga (price), dan tempat/distribusi (place).

Seorang manajer pemasaran dapat mengontrol tiap komponen bauran pemasaran, tetapi strategi untuk keempat komponen tersebut harus dipadukan untuk mencapai hasil yang maksimal, yaitu memilih produk yang tepat, harga yang pantas, saluran distribusi yang baik dan promosi yang efektif. Competitive Positioning adalah metode-metode yang digunakan agar perusahaan dapat mengembangkan posisi relatifnya dibandingkan dengan para pesaing. Jika perusahaan berhasil memperoleh dan mempertahankan lokasi yang strategis, maka itu dapat menjadi rintangan yang efektif bagi para pesaing untuk mendapatkan akses ke pasar (Tjiptono dan Chandra, 2011).

\section{Indikator Lokasi}

Indikator pemilihan lokasi fisik menurut Tjiptono dan Chandra (2011), memerlukan pertimbangan cermat diantaranya: (1) Akses, yaitu lokasi yang dilalui mudah dijangkai sarana transportasi umum; (2) Visibilitas, yaitu lokasi atau tempat yang dapat dilihat dengan jelas dari jarak pandang normal; (3) Tempat parkir yang luas, nyaman dan aman; (4) Ekspansi, yaitu tersedia tempat yang cukup luas untuk perluasan usaha di kemudian hari; dan (5) Lingkungan, yaitu daerah sekitar yang mendukung jasa yang ditawarkan. Suatu lokasi disebut strategis bila berada dipusat kota, kepadatan populasi, kemudahan mencapainya menyangkut kemudahan transportasi umum, kelancaran lalu lintas dan arahnya tidak membingungkan konsumen. Sejalan dengan semakin menjamurnya bisnis atau usaha yang menawarkan produk atau jasa yang sejenis, perbedaan yang sangat tipis sekalipun pada lokasi dapat berdampak kuat pada pangsa pasar dan kemampuaan sebuah usaha. Di samping itu, keputusan pemilihan suatu lokasi juga mencerminkan komitmen jangka panjang perusahaan dalam hal keuangan, karena merubah lokasi yang buruk kadangkala sulit dilakukan dan sangat mahal (Nugroho dan Paramita, 2009).

Sehingga definisi kualitas pelayanan dapat diartikan sebagai upaya pemenuhan kebutuhan dan keinginan konsumen serta ketepatan penyampaiannya dalam mengimbangi harapan konsumen Tjiptono dan Chandra (2011). Menyatakan bahwa kualitas pelayanan didefinisikan penilaian pelanggan atas keunggulan atau keistimewaan suatu produk atau layanan secara menyeluruh. Kualitas pelayanan dapat diketahui dengan cara membandingkan persepsi para konsumen atas pelayanan yang diterima dengan pelayanan yang sesungguhnya konsumen harapkan terhadap atribut-atribut pelayanan suatu perusahaan (Parasuraman, 2008).

\section{Indikator Kualitas Pelayanan}

Kualitas pelayanan (service quality) dapat diukur dengan menggunakan lima dimensi. Menurut Tjiptono dan Chandra (2011 adalah: (1) Bukti langsung (tangibles), meliputi fasilitas fisik, perlengkapan, pegawai dan sarana komunikasi; (2) Reliabilitas (reliability), kemampuan untuk memberikan pelayanan yang dijanjikan dengan segera, akurat dan memuaskan; (3) Daya tanggap (responsiveness), yaitu Daya tanggap yaitu keinginan para staf untuk membantu para pclanggan dan memberikan layanan dengan tanggap, yakni motivasi para karyawan dalam 
memecahkan masalah yang dihadapi pelanggan dalam mengunakan jasa; (4) Jaminan/keyakinan (assurance), yaitu pengetahuan dan kesopansantunan para pegawai perusahaan serta kemampuan menumbuhkan rasa percaya para konsumennya kepada perusahaan; dan (5) Empati (empathy), meliputi kemudahaan melakukan hubungan, komunikasi yang baik, perhatian pribadi dan memahami kebutuhan para pelanggan.

Pelayanan yang berkualitas menurut View (2010) adalah kemampuan suatu perusahaan menyajikan atau memenuhi apa yang dijanjikannya kepada pelanggan. Thomson, De Souza, dan Gale menyatakan bahwa salah satu strategi sehubungan dengan sukses dalam bisnis jasa adalah delivery of high service quality (pemberian kualitas yang baik). Menurut Dari berbagai definisi diatas, dapat ditarik kesimpulan bahwa pada dasarnya pengertian kepuasan pelanggan mencakup perbedaan antara harapan dan kinerja atau hasil yang dirasakan. Penilaian kepuasan pelanggan mempunyai tiga bentuk yang berbeda, yaitu: Positive disconfirmation, dimana kinerja lebih baik dari harapan; Simple confirmation, dimana kinerja sama dengan harapan; dan Negative disconfirmation, dimana kinerja lebih buruk dari harapan.

\section{Indikator Kepuasan Pelanggan}

Keller (2009) mengungkapkan kepuasan pelanggan adalah perasaan senang atau kecewa seseorang yang berasal dari perbandingan antara kesannya terhadap kinerja (atau hasil) suatu produk dan harapan-harapannya. Kepuasan pelanggan dapat diukur dengan beberapa indikator yaitu, Yuliarmi dan Riyasa (2007): (1) Kesesuaian kualitas pelayanan dengan tingkat harapan; (2)

Tingkat kepuasan apabila dibandingkan dengan yang sejenis; (3) Tidak ada pengaduan atau komplain yang dilayangkan (Anderson dan Lehman (2008)

\section{METODE}

Setelah semua data telah terkumpul maka langkah berikutnya dalam penelitian ini adalah analisis data. Tujuan analisis ini adalah untuk menginterpretasikan dan menarik kesimpulan dari sejumlah data yang terkumpul. Adapun metode analisa data yang digunakan dalam penelitian ini adalah Skala Likert dan Analisis linier berganda.

\section{Skala Likert}

Indikator-indikator diukur dengan skala penilaian Likert yang memiliki lima tingkat prefensi jawaban yang masing-masing mempunyai nilai skor 1-5 dengan rincian sebagai berikut: 1 = Sangat tidak puas; 2 = Tidak puas; 3 = Ragu-ragu atau netral; $4=$ Puas; dan $5=$ Sangat puas. Skala Likert merupakan skala yang dipakai untuk mengukur sikap, pendapat dan presepsi seseorang / sekelompok orang tentang fenomena sosial (Sugiyono, 2010). Menurut Sugiyono (2010) analisa dilakukan dengan menggunakan nilai indeks yaitu dengan menentukan nilai besarnya kelas sebagai berikut : Nilai maksimum : 5 dan Nilai minimum $: 1$

$\begin{array}{ll}\text { Rentang Skala }(\mathrm{RS})= & \frac{\text { Nilai Maksimum-Nilai Minimur }}{\text { Jumlah Kelas }} \\ \text { Rentang Skala }(\mathrm{RS})= & \frac{(5-1)}{5}=0,8\end{array}$

Sehingga tabel indeks penilaiannya adalah sebagai berikut :

Tabel 1. Rentang Skala Indeks Penilaian

\begin{tabular}{l} 
Nilai Indeks \\
\hline $1<\mathrm{x} \leq 1,8$ \\
$1,8<\mathrm{x} \leq 2,6$ \\
$2,6<\mathrm{x} \leq 3,4$ \\
$3,4<\mathrm{x} \leq 4,2$ \\
$4,2<\mathrm{x} \leq 5$ \\
\hline
\end{tabular}
Penilaian

Sangat Tidak Baik

Tidak Baik

Ragu-ragu/Netral

Baik/Strategis

Sangat Baik

\section{Teori Metode Suksesif Interval}

Metode suksesif interval (Methode of successive interval) merupakan proses mengubah data ordinal menjadi data interval. Data interval sebenarnya adalah data kualitatif atau bukan 
angka yang sebenarnya. Data ordinal menggunakan angka sebagai simbol data kualitatif. Angka 1 mewakili "Sangat Tidak Baik"; Angka 2 mewakili "Tidak Baik"; Angka 3 mewakili "Cukup Baik"; Angka 4 mewakili "Baik"; Angka 5 mewakili "Sangat Baik". Dalam banyak prosedur statistik seperti regresi, korelasi, uji t dan lain sebagainya mengharuskan data berskala interval. Oleh karena itu, jika kita hanya mempunyai data berskala ordinal, maka data tersebut harus diubah kedalam bentuk interval untuk memenuhi persyaratan prosedur-prosedur tersebut. Kecuali jika kita menggunakan prosedur seperti korelasi Spearman yang mengizinkan data berskala ordinal, maka kita tidak perlu mengubah data yang sudah ada tersebut.

\section{Alat Analisa \\ Uji Validitas}

Uji validitas digunakan untuk mengukur valid atau tidaknya suatu kuesioner dalam pengumpulan data. Uji validitas ini dilakukan untuk mengetahui apakah item pernyataan dalam kuesioner mampu mengungkapkan dengan pasti apa yang diteliti. (Arikunto, 2010). Kriteria pengambilan keputusan adalah : Jika $R_{\text {hitung }}>R_{\text {tabel }}$ maka dinyatakan valid; Jika $R_{\text {hitung }}<$ $\mathrm{R}_{\text {tabel }}$ maka dinyatakan tidak valid

\section{Uji Reliabilitas}

Uji Reliabilitas digunakan untuk menguji tingkat ketepatan yang konstan atau tidak. Disamping itu uji reliabilitas dimaksudkan untuk mengetahui adanya konsistensi alat ukur dalam penggunaannya. Adapun cara yang digunakan untuk menguji reliabilitas kuesioner dalam penelitian ini adalah mengukur reliabilitas dengan uji statistik Cronbach's Alpha. Untuk mengetahui kuesioner tersebut sudah reliabel akan dilakukan pengujian reliabilitas kuesioner dengan bantuan program komputer SPSS.

\section{Analisis Regresi Linear Berganda}

Suatu cara yang digunakan untuk mengolah hasil penelitian guna memperoleh suatu kesimpulan. Adapun metode pengolahan data yang digunakan adalah Analisis Regresi Linear Berganda. Untuk mengetahui pengaruh antara Lokasi $\left(\mathrm{X}_{1}\right)$ dan Kualitas Pelayanan $\left(\mathrm{X}_{2}\right)$ terhadap Kepuasan Pelanggan (Y). Menghitung persamaan Regresi Berganda dengan rumus :

$\mathrm{Y}=\mathrm{a}+\mathrm{b}_{1} \mathrm{X}_{1}+\mathrm{b}_{2} \mathrm{X}_{2}$

Keterangan : $\mathrm{Y}=$ Variabel Kepuasan Pelanggan; $\mathrm{a}=$ Konstanta; $\mathrm{b}_{1}, \mathrm{~b}_{2},=$ Koefisien Regresi; $\mathrm{X}_{1}=$ Lokasi

$\mathrm{X}_{2}=$ Kualitas Pelayanan

\section{HASIL}

\section{Tanggapan responden terhadap Lokasi Jasa Pengiriman JNE di Muara Bulian}

Untuk mengetahui tanggapan responden terhadap Lokasi Jasa Pengiriman JNE di Muara Buliandapat dilihat pada Tabel 2 sebagai berikut :

\section{Tabel 2. Tanggapan Responden terhadap Lokasi Jasa Pengiriman JNE di Muara Bulian}

\begin{tabular}{|c|c|c|c|c|c|c|c|c|}
\hline No & Pernyataan & STS & TS & $\mathbf{R}$ & $\mathbf{S}$ & SS & $\Sigma$ & Indeks \\
\hline \multirow[t]{2}{*}{1} & $\begin{array}{l}\text { Akses menuju JNE Muara Bulian } \\
\text { mudah dijangkau dan tidak }\end{array}$ & & 11 & 28 & 21 & 21 & 295 & 3,64 \\
\hline & macet & & 22 & 84 & 84 & 105 & & \\
\hline \multirow[t]{2}{*}{2} & Lokasi JNE Muara Bulian dekat & & 16 & 41 & 22 & 15 & 318 & 3,92 \\
\hline & dan terlihat dari jalan raya & & 32 & 123 & 88 & 75 & & \\
\hline \multirow[t]{2}{*}{3} & $\begin{array}{l}\text { JNE Muara Bulian mempunyai } \\
\text { tempat parkir yang luas dan }\end{array}$ & & 33 & 28 & 7 & 13 & 243 & 3,00 \\
\hline & aman & & 66 & 84 & 28 & 65 & & \\
\hline \multirow[t]{2}{*}{4} & $\begin{array}{l}\text { Lokasi JNE Muara Bulian } \\
\text { kesediaan tempat cukup luas }\end{array}$ & & 9 & 32 & 21 & 19 & 293 & 3,61 \\
\hline & untuk perluasan usaha & & 18 & 96 & 84 & 95 & & \\
\hline 5 & $\begin{array}{l}\text { Lingkungan JNE Muara Bulian } \\
\text { mendukung untuk jasa yang }\end{array}$ & & 16 & 26 & 17 & 22 & 288 & 3,55 \\
\hline
\end{tabular}


Pengaruh Lokasi dan Kualitas Pelayanan Terhadap Kepuasan Pelanggan Pada Jasa Pengiriman J \& T di Muara Bulian

ditawarkan

$32 \quad 78 \quad 68 \quad 110$

Rata-rata Indeks

Sumber: Data primer yang diolah

analisis yang dilakukan, indeks tertinggi terdapat pada pernyataan Lokasi JNE Muara Bulian dekat dan terlihat dari jalan rayadengan nilai indeks 3,92 yang artinya masuk dalam kriteria baik. Indeks terendah terdapat pada JNE Muara Bulian mempunyai tempat parkir yang luas dan amandengan nilai indeks 3,00 yang artinya masuk dalam kriterianetral. Sedangkan rata-rata indeks 3,54 yang artinya Lokasi Jasa Pengiriman JNE di Muara Bulian sudah Strategis.

\section{Tanggapan responden terhadap Kualitas Pelayanan pada Jasa Pengiriman JNE di Muara Bulian}

Untuk mengetahui tanggapan responden terhadap Kualitas Pelayanan pada Jasa Pengiriman JNE di Muara Buliandapat dilihat pada Tabel 3 sebagai berikut :

Tabel 3. Tanggapan Responden terhadap Kualitas Pelayanan pada Jasa Pengiriman JNE di Muara Bulian

\begin{tabular}{|c|c|c|c|c|c|c|c|c|}
\hline No & Pernyataan & STS & TS & $\mathbf{R}$ & $\mathbf{S}$ & SS & $\boldsymbol{\Sigma}$ & Indeks \\
\hline \multirow[t]{2}{*}{1} & Karyawan JNE Muara Bulian selalu & & 22 & 19 & 22 & 18 & 279 & 3,44 \\
\hline & cepat dalam menyelesaikan pekerjaan & & 44 & 57 & 88 & 90 & & \\
\hline \multirow[t]{2}{*}{2} & $\begin{array}{l}\text { Karyawan JNE Muara Bulian selalu } \\
\text { tanggap terhadap keluhan yang }\end{array}$ & & 10 & 23 & 28 & 20 & 301 & 3,71 \\
\hline & diajukan pelanggan & & 20 & 69 & 112 & 100 & & \\
\hline \multirow[t]{2}{*}{3} & $\begin{array}{l}\text { Karyawan JNE Muara Bulian selalu } \\
\text { memberikan perhatian individu }\end{array}$ & & 12 & 34 & 26 & 9 & 276 & 3,40 \\
\hline & dengan baik kepada pelanggan & & 24 & 103 & 104 & 45 & & \\
\hline \multirow[t]{2}{*}{4} & $\begin{array}{l}\text { Karyawan JNE Muara Bulian mampu } \\
\text { memecahkan masalah yang dihadapi }\end{array}$ & & 21 & 27 & 19 & 14 & 269 & 3,32 \\
\hline & pelanggan dalam menggunakan jasa & & 42 & 81 & 76 & 70 & & \\
\hline \multirow[t]{2}{*}{5} & $\begin{array}{l}\text { Karyawan JNE Muara Bulian sopan } \\
\text { santun dan ramah dalam }\end{array}$ & & 17 & 31 & 13 & 20 & 279 & 3,44 \\
\hline & $\begin{array}{l}\text { memberikan pelayanan } \\
\text { Rata-rata Indeks }\end{array}$ & & 34 & 93 & 52 & 100 & & 3,39 \\
\hline
\end{tabular}

Sumber: Data primer yang diolah

analisis yang dilakukan, indeks tertinggi terdapat pada pernyataan Karyawan JNE Muara Bulian selalu tanggap terhadap keluhan yang diajukan pelanggandengan nilai indeks 3,71 yang artinya masuk dalam kriteriabaik. Indeks terendah terdapat pada pernyataan Karyawan JNE Muara Bulian mampu memecahkan masalah yang dihadapi pelanggan dalam menggunakan jasadengan nilai indeks 3,32 yang artinya masuk dalam kriteriabaik. Sedangkan rata-rata indeks 3,39 yang artinya Kualitas Pelayanan pada Jasa Pengiriman JNE di Muara Bulian sudah Baik

\section{Tanggapan responden terhadap Kepuasan Pelanggan pada Jasa Pengiriman JNE di Muara Bulian}

Untuk mengetahui tanggapan responden terhadap Kepuasan Pelanggan dari analisis yang dilakukan, indeks tertinggi terdapat pada pernyataan Saya merasa puas dengan pelayanan yang diberikan karyawan pada jasa pengiriman JNE Muara Bulian dengan nilai indeks 3,86 yang artinya masuk dalam kriteria baik. Indeks terendah terdapat pada pernyataan Pelanggan merasa JNE Muara Bulian adalah jasa pengiriman dengan reputasi yang baikdengan nilai indeks 3,34 yang artinya masuk dalam kriteria baik. Sedangkan rata-rata indeks 3,60 yang artinya Kepuasan pelanggan pada Jasa Pengiriman JNE di Muara Bulian sudah Baik 
Pengaruh Lokasi dan Kualitas Pelayanan Terhadap Kepuasan Pelanggan Pada Jasa Pengiriman J \& T di Muara Bulian

\section{Pengaruh Lokasi dan Kualitas Pelayanan terhadap Kepuasan Pelanggan pada Jasa Pengiriman JNE di Muara Bulian}

Untuk mengetahui besarnya Pengaruh Lokasi dan Kualitas Pelayanan terhadap Kepuasan Pelanggan pada Jasa Pengiriman JNE di Muara Bulian digunakan alat analisis persamaan regresi linear berganda, pengujian hipotesis melalui uji $t$, uji $F$, koefisien determinasi. Data diolah dengan bantuan komputer yaitu dengan menggunakan program SPSS versi 20.0.

\section{Uji Validitas}

Uji validitas digunakan untuk mengukur sah atau tidaknya suatu kuesioner. Dasar pengambilan keputusan yang digunakan adalah melakukan uji signifikasi dengan membandingkan nilai $\mathrm{r}$ hitung dengan $\mathrm{r}$ tabel. Untuk sampel 81 orang maka nilai $\mathrm{r}$ tabel adalah 0,2159. Maka hasil analisisnya adalah sebagai berikut:

Tabel 4. Uji Validitas

\begin{tabular}{lccc}
\hline Indikator & r hitung & r tabel & Keterangan \\
\hline Lokasi & 0,316 & 0,2159 & Valid \\
P1 & 0,238 & 0,2159 & Valid \\
P2 & 0,393 & 0,2159 & Valid \\
P3 & 0,978 & 0,2159 & Valid \\
P4 & 0,943 & 0,2159 & Valid \\
P5 & & & \\
Kualitas Pelayanan & 0,306 & 0,2159 & Valid \\
P1 & 0,341 & 0,2159 & Valid \\
P2 & 0,345 & 0,2159 & Valid \\
P3 & 0,304 & 0,2159 & Valid \\
P4 & 0,554 & 0,2159 & Valid \\
P5 & & & \\
Kepuasan Pelanggan & 0,340 & 0,2159 & Valid \\
P1 & 0,302 & 0,2159 & Valid \\
P2 & 0,422 & 0,2159 & Valid \\
P3 & 0,339 & 0,2159 & Valid \\
P4 & 0,710 & 0,2159 & Valid \\
P5 & & &
\end{tabular}

Sumber: Data primer yang diolah

Tabel 4 diatas dapat dijelaskan jika $\mathrm{r}$ hitung $>\mathrm{r}$ tabel maka dapat disimpulkan bahwa semua item pernyataan dalam indikator variabel Lokasi $\left(\mathrm{X}_{1}\right)$, Kualitas Pelayanan $\left(\mathrm{X}_{2}\right)$ dan Kepuasan Pelanggan (Y) semua item pernyataan valid.

\section{Uji Reliabilitas}

Uji Reliabilitas digunakan untuk mengukur konsistensi variabel dari waktu ke waktu. Dalam uji reliabilitas, suatu variabel dinyatakan reliabel jika mempunyai nilai Cronbach alpha lebih besar dari 0,600 (Ghozali, 2013). Hasil uji reliabilitas dapat dilihat dari Tabel 5 berikut ini:

Tabel 5. Uji Reliabilitas

\begin{tabular}{llll}
\hline Variabel & Cronbach Alpha & Taraf Signifikan & Keterangan \\
\hline Lokasi $\left(\mathrm{X}_{1}\right)$ & 0,634 & 0,6 & Reliabel \\
Kualitas Pelayanan $\left(\mathrm{X}_{2}\right)$ & 0,620 & 0,6 & Reliabel \\
Kepuasan Pelanggan $(\mathrm{Y})$ & 0,652 & 0,6 & Reliabel \\
\hline
\end{tabular}

Sumber: Data primer yang diolah 
Pengaruh Lokasi dan Kualitas Pelayanan Terhadap Kepuasan Pelanggan Pada Jasa Pengiriman J \& T di Muara Bulian

Berdasarkan Tabel 5 diatas dapat dijelaskan bahwa variabel Lokasi $\left(\mathrm{X}_{1}\right)$ dan Kualitas Pelayanan $\left(\mathrm{X}_{2}\right)$ masing-masing diperoleh nilai cronbach alpha 0,634 dan 0,620dengan taraf signifikan 0,6 ini menunjukkan bahwa cronbach alpha lebih besar dari taraf signifikan. Sedangkan variabel Kepuasan Pelanggannilai cronbach alpha0,652sehingga dengan demikian hasil dari uji reliabilitas pada variabel ini adalah reliabel.

\section{Regresi Linier Berganda}

Untuk menganalisis Pengaruh Lokasi dan Kualitas Pelayanan terhadap Kepuasan Pelanggan pada Jasa Pengiriman JNE di Muara Bulian dilakukan pengujian dan pembuktian pengaruh tersebut digunakan analisis regresi linier berganda. Hasil perhitungan regresi linier berganda dengan program SPSS versi 20.0 dari tabel koefisien diperoleh persamaan sebagai berikut

Tabel 6. Regresi Linear Berganda

\begin{tabular}{|c|c|c|c|c|c|}
\hline \multirow[b]{2}{*}{ Model } & \multicolumn{2}{|c|}{$\begin{array}{l}\text { Unstandardized } \\
\text { Coefficients }\end{array}$} & \multirow{2}{*}{\begin{tabular}{|l|}
$\begin{array}{l}\text { Standardized } \\
\text { Coefficients }\end{array}$ \\
Beta
\end{tabular}} & \multirow[b]{2}{*}{$\mathrm{t}$} & \multirow[b]{2}{*}{ Sig. } \\
\hline & B & Std. Error & & & \\
\hline 1 (Constant) & 5.892 & 2.159 & & 2.729 & .008 \\
\hline LOKASI & .467 & .132 & .406 & 3.545 & .001 \\
\hline KUALITAS PELAYANAN & .169 & .119 & .163 & 1.721 & .159 \\
\hline
\end{tabular}

Sumber: data olahan

Hasil perhitungan Regresi Linear Berganda dengan program spss versi 20.0 dari tabel koefisien yang dilihat pada tabel 5.6 diatas, diperoleh persamaan sebagai berikut :

$\mathrm{Y}=\mathrm{a}+\mathrm{b}_{1} \mathrm{X}_{1}+\mathrm{b}_{2} \mathrm{X}_{2}$

$\mathrm{Y}=5,892+0,467(\mathrm{X} 1)+0,169(\mathrm{X} 2)$

Persamaan diatas dapat dijelaskan Bahwa nilai a (Konstanta) sebesar 5,892 dan nilai koefisien regresi atau nilai pengaruh $b_{1}$ sebesar 0,467 dan nilai pengaruh $b_{2}$ sebesar 0,169 . Ini menjelaskan berarti terdapat pengaruh yang positif dalam penelitian ini. Persamaan diatas juga dapat diartikan sebagai berikut

1. $\mathrm{a}=5,892$, Artinya apabila variabel Lokasi dan Kualitas Pelayanan bernilai nol maka Kepuasan Pelanggan sebesar 5,892.

2. $\mathrm{b}_{1} \mathrm{X}_{1}=$ Lokasi $=0,467$, Artinya apabila variabel Lokasinaik sebesar satu satuan maka Kepuasan Pelanggan akan meningkat sebesar 0,467 satuan dengan asumsi variabel Kualitas Pelayanan tetap.

3. $\mathrm{b}_{2} \mathrm{X}_{2}=$ Kualitas Pelayanan $=0,169$, Artinya apabila variabel Kualitas Pelayanan naik sebesar satu satuan maka Kepuasan Pelanggan akan meningkat sebesar 0,169 satuan dengan asumsi variabel Lokasi tetap.

\section{Pengujian Hipotesis \\ Uji t}

Uji t digunakan untuk menguji tingkat signifikan pengaruh variabel independen pada variabel dependen secara parsial (individu). Yang mana hasil uji t juga dapat dilihat pada tabel 5.6 diatas (Coefficients).

Diuji dengan tingkat signifikan df $81-2-1=78$ (t Tabel $=1,665)$.

1. Lokasi $\left(\mathrm{X}_{1}\right)$ dengan angka thitung sebesar 3,545 lebih besar dari t tabel 1,665 $(3,545>1,665)$. Dapat disimpulkan bahwa Lokasimempunyai pengaruh terhadapKepuasan Pelanggan.

2. Kualitas Pelayanan $\left(\mathrm{X}_{2}\right)$ dengan angka t hitung sebesar 1,721 lebih besar dari t tabel 1,665 $(1,721$ >1,665). Dapat disimpulkan bahwa Kualitas Pelayanan mempunyai pengaruh terhadapKepuasan Pelanggan 
Pengaruh Lokasi dan Kualitas Pelayanan Terhadap Kepuasan Pelanggan Pada Jasa Pengiriman J \& T di Muara Bulian

\section{Uji F}

Untuk menguji tentang adanya pengaruh yang signifikan antara variabel Lokasi $\left(\mathrm{X}_{1}\right)$ dan Kualitas Pelayanan $\left(\mathrm{X}_{2}\right)$ secara bersama sama terhadap Kepuasan pelanggandigunakan analisis uji $\mathrm{F}$ dengan cara membandingkan $\mathrm{F}$ hitung dan $\mathrm{F}$ tabel. Untuk mempermudah pengujian ini, maka penulis menggunakan SPSS 20.0 yang hasilnya dapat dilihat di tabel Anova sebagai berikut:

Tabel 7. Anova

\begin{tabular}{|l|r|r|r|r|r|}
\hline \multicolumn{1}{|c|}{ Model } & Sum of Squares & df & Mean Square & \multicolumn{1}{c|}{ F } & Sig. \\
\hline 1 Regression & 704.389 & 2 & 352.194 & 13.730 & $.000^{a}$ \\
Residual & 2000.747 & 78 & 25.651 & & \\
Total & 2705.136 & 80 & & & \\
\hline
\end{tabular}

Sumber: data olahan

Pada tingkat kepercayaan $(\mathrm{a}=0,05)$ dan $\mathrm{df} 2: 78$ diperoleh nilai $\mathrm{F}$ tabel sebesar 3,11 sedangkan nilai $\mathrm{F}$ hitung 13,730dengan demikian nilai $\mathrm{F}$ hitung $>\mathrm{F}$ tabel. Jadi terbukti bahwa ada pengaruh antara Lokasi dan Kualitas Pelayanansecara bersama-sama terhadap Kepuasan Pelanggan pada Jasa Pengiriman JNE di Muara Bulian.

\section{Koefisien Determinasi $\left(R^{2}\right)$}

Analisis koefisien determinasi digunakan untuk mengetahui Persentase sumbangan pengaruh variabel independen Lokasi $\left(\mathrm{X}_{1}\right)$ dan Kualitas Pelayanan (X2) terhadap variabel dependen Kepuasan Pelanggan (Y) seperti hasil pengolahan SPSS dibawsah ini:

Tabel 8. Koefisien Determinasi

\begin{tabular}{|l|l|l|l|l|}
\hline Model & $\mathrm{R}$ & $\mathrm{R}$ Square & Adjusted R Square & Std. Error of the Estimate \\
\hline 1 & $.510^{\mathrm{a}}$ & .260 & .241 & 5.065 \\
\hline
\end{tabular}

Sumber: data olahan

Berdasarkan tabel summary diatas diperoleh nilai Adjust R Squre yang diperoleh adalah sebesar 0,241 yang artinya Pengaruh Lokasi dan Kualitas Pelayanan terhadap Kepuasan Pelanggan pada Jasa Pengiriman JNE di Muara Buliansebesar 24,1\% sedangkan sisanya sebesar $75,9 \%$ disebabkan faktor lain yang tidak termasuk dalam penelitian ini.

\section{SIMPULAN}

Hasil penelitian yang berjudul Pengaruh Lokasi dan Kualitas Pelayanan terhadap Kepuasan Pelangan pada Jasa Pengiriman JNE di Muara Bulian dapat disimpulkan sebagai berikut :

1. Tanggapan responden terhadap Lokasi pada Jasa Pengiriman JNE di Muara Bulianditunjukkan dengan nilai indeks rata-rata sebesar 3,54 yang artinya Lokasi pada Jasa Pengiriman JNE sudah strategis

2. Tanggapan responden terhadap Kualitas Pelayanan pada Jasa Pengiriman JNE di Muara Bulian ditunjukkan dengan nilai indeks rata-rata sebesar 3,39 yang artinya Kualitas Pelayanan pada Jasa Pengiriman JNE di Muara Bulian sudah baik

3. Tanggapan responden terhadap Kepuasan Pelanggan pada Jasa Pengiriman JNE di Muara Bulian ditunjukkan dengan nilai indeks rata-rata sebesar 3,60 yang artinya Kepuasan Pelanggan pada Jasa Pengiriman JNE di Muara Bulian sudah baik.

4. Pengaruh Lokasi dan Kualitas Pelayanan terhadap Kepuasan Pelanggan pada Jasa Pengiriman JNE di Muara Buliandapat disimpulkan dari uji t, uji $F$ dan $\mathrm{R}^{2}$. Untuk Uji $t$ Lokasi $\left(\mathrm{X}_{1}\right)$ dengan angka $\mathrm{t}$ hitung sebesar 3,545 lebih besar dari t tabel 1,665. Dapat disimpulkan bahwa Lokasi mempunyai pengaruh terhadap Kepuasan Pelanggan. Kualitas 
Pelayanan $\left(\mathrm{X}_{2}\right)$ dengan angka t hitung sebesar 1,721 lebih besar dari t tabel 1,665. Dapat disimpulkan bahwa Kualitas Pelayanan mempunyai pengaruh terhadap Kepuasan Pelanggan. Pada tingkat kepercayaan $(a=0,05)$ dan df $2: 78$ diperoleh nilai $F$ tabel sebesar 3,11 sedangkan nilai $\mathrm{F}$ hitung 13,730 dengan demikian nilai $\mathrm{F}$ hitung $>\mathrm{F}$ tabel. Jadi terbukti bahwa ada pengaruh antara Lokasi dan Kualitas Pelayanan secara bersama-sama terhadap Kepuasan Pelanggan pada Jasa Pengiriman JNE di Muara Bulian. Dari tabel summary diperoleh nilai Adjust $\mathrm{R}$ Squre yang diperoleh adalah sebesar 0,241 yang artinya Pengaruh Lokasi dan Kualitas Pelayanan terhadap Kepuasan Pelanggan pada Jasa Pengiriman JNE di Muara Bulian sebesar 24,1\% sedangkan sisanya sebesar 75,9\% disebabkan faktor lain yang tidak termasuk dalam penelitian ini.

\section{DAFTAR PUSTAKA}

Adisetiawan, R., 2016, Faktor yang Mempengaruhi Lulusan SMA dalam Memilih Fakultas Ekonomi Program Studi Manajemen Universitas Batanghari, Jurnal Imiah Universitass Batanghari Jambi, 16(3), 1-11

Adisetiawan, R., 2017, Performance Mahasiswa Fakultas Ekonomi Universitas Batanghari Jambi, Jurnal Mmiah Universitas Batanghari, 14(3), 1-10

Ghozali, Imam. 2013. Aplikasi Analisis Multivariate dengan Program IBM SPSS 21. Semarang: Badan Penerbit Universitas Diponegoro.

Kotler dan Keller, 2009, Manajemen Pemasaran, Jilid 1 Edisi Ke 13 Jakarta Erlangga Tjiptono \& Chandra. 2011. Service, Quality \& Satisfaction. Yogyakarta: Andi Offset. 